\title{
Hypoglycaemia and pleural tumours
}

\section{To the Editors:}

We read with interest the article by Metintas et al. [1] on nonmalignant pleural lesions and their association with asbestos exposure. It is worth noting that another form of pleural-based tumour, solitary fibrous tumour, remains a distinct entity and interestingly has not been linked to asbestos exposure $[2,3]$. Asbestos usually causes more diffuse forms of pleural lesions [4]. Solitary fibrous tumours are rare tumours with a $12-13 \%$ rate of malignancy.

We recall an interesting case of a 93-yr-old male, who was a resident at a home for the elderly, with a history of pulmonary tuberculosis and exposure to asbestos. He presented to us with recurrent episodes of decreased consciousness, particularly in the morning. Glucose concentrations of between 1.8$2.5 \mathrm{mmol} \cdot \mathrm{L}^{-1}$ were recorded during the attacks. He did not have postural hypotension and had a normal blood count, and liver, bone, thyroid and renal function profiles. Furthermore, his growth hormone and insulin-like-growth factor (IGF)-I levels and short synacthen test were also unremarkable. Chest radiographs revealed a huge dumb-bell shaped calcified mass occupying almost the entire left hemithorax (fig. 1a). Computed tomography (fig. 1b) showed features consistent with a large solitary fibrous tumour, which was confirmed by fine-needle aspiration. Insulin and c-peptide levels were
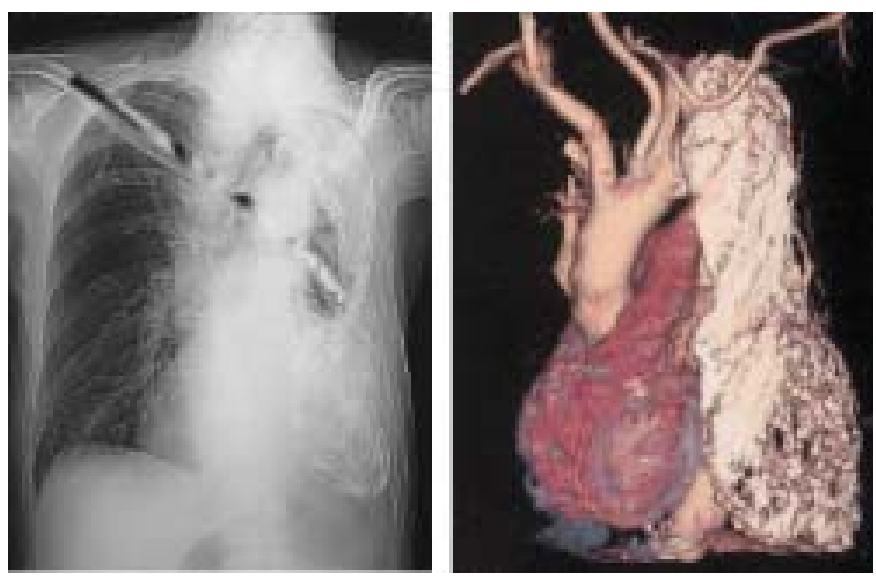

FIGURE 1. a) Chest radiograph of solitary fibrous tumour occupying almost the entire left hemithorax. b) Computed tomography scan with three-dimensional reconstruction of the large left pleural tumour. measured to exclude insulinoma, and the uncommon diagnosis of Doege-Potter syndrome was made.

In 1930, K.W. Doege and R.P. Potter, who was a radiologist, first reported the association between intrathoracic fibrous tumour and hypoglycaemia. The syndrome of hypoglycaemia is seen in $<5 \%$ of cases of solitary fibrous tumours, and is usually associated with tumours that are large with a high mitotic rate. The postulated mechanisms include tumourinduced augmented glucose utilisation and tumour IGF II production. Surgical resection of the tumour is usually curative [5], however, our patient declined surgery. Other less invasive forms of therapy, such as radiofrequency ablation and arterial embolisation of the tumour, were also declined. The patient opted for conservative treatment by intravenous dextrose.

Clinicians should be aware of this rare, but important cause of recurrent hypoglycaemia, and exclude pleural tumour in the assessment of their patients.

\section{C.S.H. Ng, C.Y.H. Wong, T.W. Lee and A.P.C. Yim}

The Chinese University of Hong Kong, Hong Kong.

\section{REFERENCES}

1 Metintas M, Metintas S, Hillerdal G, et al. Nonmalignant pleural lesions due to environmental exposure to asbestos: a field-based, cross-sectional study. Eur Respir J 2005; 26: 875-880.

2 Magdeleinat P, Alifano M, Petino A, et al. Solitary fibrous tumors of the pleura: clinical characteristics, surgical treatment and outcome. Eur J Cardiothorac Surg 2002; 21: 1087-1093.

3 Briselli M, Mark EJ, Dickersin GR. Solitary fibrous tumors of the pleura: eight new cases and review of 360 cases in the literature. Cancer 1981; 47: 2678-2689.

4 Tagliabue F, Vertemati G, Confalonieri G, Romelli A, Terragni S, Costa M. Benign solitary fibrous tumour of the pleura: a clinical review and report of six cases. Chir Ital 2005; 57: 649-653.

5 Chamberlain MH, Taggart DP. Solitary fibrous tumor associated with hypoglycemia: an example of the DoegePotter syndrome. J Thorac Cardiovasc Surg 2000; 119: 185-187. 